\title{
Variabilidade Genética entre Populações de Pistia stratiotes ${ }^{1}$
}

\author{
Genetic Diversity of Pistia stratiotes Populations
}

\author{
CARDOSO, L.R. ${ }^{2}$, MARTINS, D. ${ }^{3}$, MORI, E.S. ${ }^{3}$ e TERRA, M.A. ${ }^{4}$
}

\begin{abstract}
RESUMO - O manejo de plantas daninhas em ambientes aquáticos requer cuidado diferencial e específico, a fim de evitar a contaminação ou alteração nas funções dos corpos hídricos e otimização do custo-benefício das operações. O estudo das características genéticas de populações de plantas daninhas aquáticas fornece informações que podem auxiliar no seu controle e manejo. A alface-d'água é uma planta aquática flutuante livre amplamente distribuída em todo o Brasil, mas é em ambientes aquáticos eutrofizados que essa e outras espécies de rápido desenvolvimento causam problemas sociais e econômicos, devido à grande massa vegetal produzida. Este estudo caracterizou geneticamente populações de alface-d'água coletadas em 15 reservatórios de hidrelétricas (Barra Bonita-BAB, Bariri-BAR, Ibitinga-IBI, Chavantes-CHA, Salto Grande-SAG, Jurumirim-JUR, Promissão-PRO JaguariJAG, Nova Avanhandava-NAV, Mogi-Guaçu-MOG, Limoeiro-LIM, Três Irmãos-TRI, Ilha Solteira-ILS, Jupiá-JUP e Porto Primavera-PPR) do Estado de São Paulo. As análises foram realizadas no NUPAM (Núcleo de Pesquisas Avançadas em Matologia), ligado à FCA/UNESP, campus de Botucatu-SP. A técnica utilizada no estudo da diversidade genética foi o RAPD. Os materiais amostrados nos reservatórios do Estado foram muito similares em sua maioria. As populações de NAV, MOG, IBI, JUR, PRO e CHA foram idênticas geneticamente. BAB e SAG, LIM e TRI também foram muito parecidas, apresentando índice de distância genética de 0,0093 e 0,0178, respectivamente. A grande maioria dos reservatórios estudados (93\%) apresentou distâncias inferiores a 0,30 , formando um grupo definido. No entanto, a população de Jupiá, em média, foi a que apresentou maior diversidade genética $(0,45)$.
\end{abstract}

Palavras-chave: alface-d'água, DNA, RAPD, planta daninha, planta aquática.

\begin{abstract}
Weed management in freshwater ecosystems requires accurate and specific care to avoid alteration and contamination in water bodies and to optimize the cost-benefit of management procedures. The study of population genetics of aquatic weed supplies data for its control and management. The waterlettuce is a floating aquatic weed widely distributed throughout Brazil; however, in eutrophic freshwater ecosystems, this and other fast-developing species cause social and economic problems due to their large production of vegetable mass. This study characterized the genetic variability of waterlettuce populations collected in 15 hydroelectric reservoirs (Barra Bonita-BAB, Bariri-BAR, Ibitinga-IBI, Chavantes-CHA, Salto Grande-SAG, Jurumirim-JUR, Promissão-PRO Jaguari-JAG, Nova Avanhandava-NAV, Mogi-Guaçú-MOG, Limoeiro-LIM, Três IrmãosTRI, Ilha Solteira-ILS, Jupiá-JUP, and Porto Primavera-PPR) in the state of São Paulo, Brazil. The analyses were carried out in NUPAM (Nucleus of Advanced Research in Weed Science) FCA/ UNESP, Campus of Botucatu-SP. RAPD markers was the technique applied to study genetic diversity. Most of the accesses sampled were very similar. The populations NAV, MOG, IBI, JUR, $P R O$, and CHA were genetically identical. BAB and SAG, and LIM and TRI were also similar presenting genetic distance of 0.0093 and 0.0178 , respectively. The majority of the reservoirs (93\%) presented genetic distance lower than 0.30, forming a specific group. However, Jupiá population, on average, presented the highest genetic diversity (0.45).
\end{abstract}

Key words: waterlettuce, DNA, RAPD, weed,aquatic plant.

1 Recebido para publicação em 19.1.2005 e na forma revisada em 1.4.2005.

2 Eng.-Agr., M.S., Dep. de Produção Vegetal/Agricultura, FCA/UNESP, Caixa Postal 237, 18603-970 Botucatu-SP; ${ }^{3}$ Professor Livre Docente, Dep. de Produção Vegetal, FCA/UNESP. ${ }^{4}$ Professor Adjunto, Departamento de Agronomia, FAG. Guaraí-TO. 


\section{INTRODUÇÃO}

Relevantes problemas causados pela ocorrência de plantas aquáticas em reservatórios de hidrelétricas no Brasil comprometem cada vez mais a eficiência do processo de geração de energia. De acordo com Tanaka (1998), a hidrelétrica de Jupiá, em alguns meses do ano, pode ser praticamente parada em razão do entupimento das grades de proteção das turbinas por grandes massas das plantas imersas Egeria densa e Egeria najas. Vários estudos estão sendo realizados na tentativa de desenvolver ou aperfeiçoar práticas de controle que minimizem os custos com a limpeza dessas grades de proteção.

A alface-d'água foi uma das espécies predominantes em levantamentos realizados nos reservatórios Barra Bonita, Bariri, Ibitinga, Promissão e Nova Avanhandava entre os anos de 2001 e 2002 (Cavenaghi et al., 2003), justificando a escolha desta planta para esse estudo de caracterização de variabilidade genética. Diversos autores, em vários trabalhos, utilizaram marcadores moleculares com a finalidade de distinguir acessos de populações de plantas aquáticas e elucidar a origem da introdução destas (Ryan, 1993a, b; Weiss, 1997).

Cardoso et al. (2002), ao determinarem a distância genética em plantas de aguapé com marcadores RAPD, revelaram uma variabilidade genética entre as populações considerada alta, visto que essa planta aquática reproduzse vegetativamente. Em acessos de egéria coletados em reservatórios de São Paulo, tanto para a espécie Egeria densa quanto para Egeria najas foram encontradas diversidades genéticas, sendo esta maior entre as populações de Egeria najas dos reservatórios de Três Irmãos e Jupiá (Martins et al., 2003).

O objetivo deste trabalho foi estudar a variabilidade genética entre acessos de alfaced'água em diferentes reservatórios de produção de energia elétrica do Estado de São Paulo.

\section{MATERIAL E MÉTODOS}

As plantas de alface-d'água foram coletadas em incursões feitas em 15 reservatórios de hidrelétricas do Estado de São Paulo (Barra Bonita-BAB, Bariri-BAR, Ibitinga-IBI, Chavantes-CHA, Salto Grande-SAG,
Jurumirim-JUR, Promissão-PRO Jaguari-JAG, Nova Avanhandava-NAV, Mogi-Guaçu-MOG, Limoeiro-LIM, Três Irmãos-TRI, Ilha SolteiraILS, Jupiá-JUP e Porto Primavera-PPR). Após a coleta, as plantas foram levadas para o Núcleo de Pesquisas Avançadas em Matologia (NUPAM), ligado ao Departamento de Produção Vegetal da Faculdade de Ciências Agronômicas, UNESP, campus de Botucatu-SP.

O DNA nuclear foi extraído de parte do material vegetal de folhas jovens, de acordo com Lodhi et al. (1994). Na análise das divergências genéticas entre as populações de alface-d'água foi empregada a técnica de RAPD (Polimorfismo de DNA Amplificado ao Acaso) com base no protocolo de Williams et al. (1990), utilizando-se os seguintes primers da Operon: G09 (CTGACGTCAC), G11 (TGCCCGTCGT), G18 (GGCTCATGTG), B10 (CTGCTGGGAC) e AK 19 (TCGCAGCGAG). As reações foram realizadas em termociclador PTC-100 da MJ Research, Inc., e posteriormente as amostras foram corridas em gel de agarose $1,5 \%$ a $110 \mathrm{~V}$, por três horas. Como marcador foram utilizados $12 \mu \mathrm{L}$ de Ladder 100 pb e $4 \mu \mathrm{L}$ de tampão de carregamento como corante, para que fosse possivel a visualização das bandas corridas no "Eagle Eye II".

A distância genética entre as populações foi estimada segundo Nei (1972), sendo as análises realizadas nos programas computacionais TFPGA-1.3 Tools for Population Genetic Analysis (Miller, 1997) e Popgene1.21 (Yeh et al., 1997).

\section{RESULTADOS E DISCUSSÃO}

Os padrões de bandas gerados pelas reações de RAPD foram nítidos e produziram bandas de média a boa intensidade. Na Figura 1 é apresentado um exemplo de padrão obtido com o primer $\mathrm{B} 10$, o qual permite a visualização das bandas de amostras referentes aos reservatórios de $\mathrm{BAB}$ e BAR.

Os primers utilizados produziram 14 marcadores dominantes, que revelaram diversidade genética entre as populações.

Na Tabela 1 estão apresentados os números e a porcentagem de locos polimórficos para cada reservatório onde foram coletadas as amostras. 


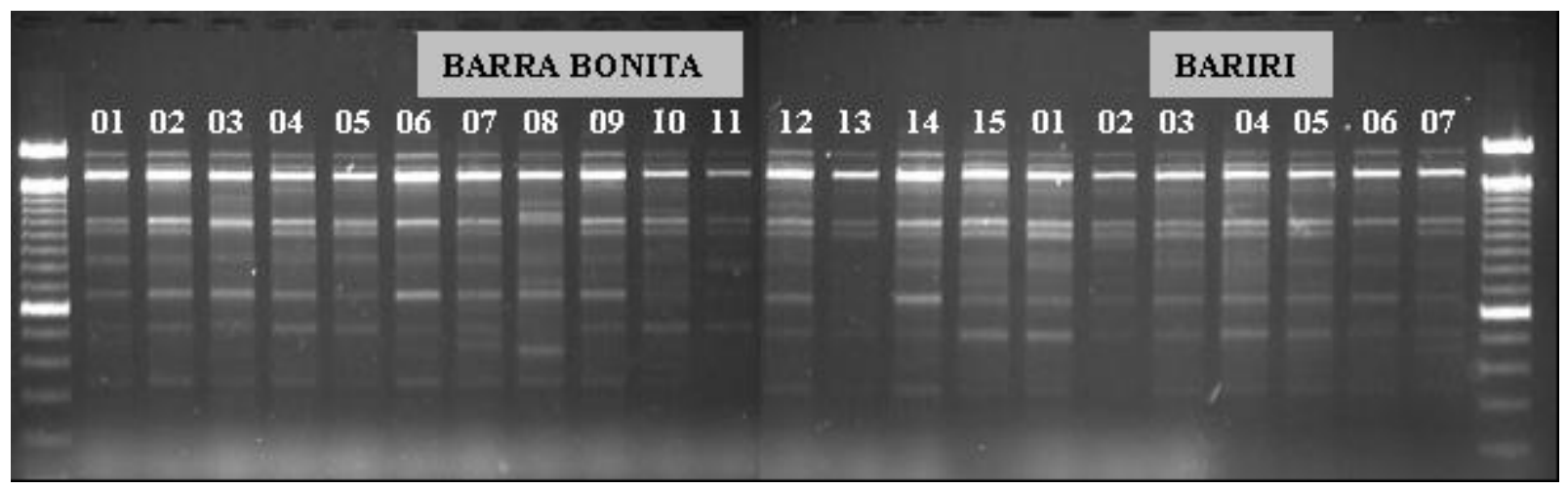

Figura 1 - Padrão de bandas amplificadas por RAPD com o primer B 10, de amostras dos reservatórios de Barra Bonita e Bariri, pertencentes ao estado de São Paulo.

Tabela 1 - Porcentagem e número de locos RAPD polimórficos para as 15 populações

\begin{tabular}{|c|c|c|}
\hline Local de coleta & $\begin{array}{l}\% \text { de locos } \\
\text { polimórficos }\end{array}$ & $\begin{array}{l}\mathrm{n}^{\mathrm{o}} \text { de locos } \\
\text { polimórfico }\end{array}$ \\
\hline Barra Bonita & 35,71 & 5 \\
\hline Bariri & 35,71 & 5 \\
\hline Ibitinga & 7,14 & 1 \\
\hline Chavantes & 0,00 & 0 \\
\hline Salto Grande & 14,29 & 2 \\
\hline Jurumirim & 0,00 & 0 \\
\hline Promissão & 0,00 & 0 \\
\hline Jaguari & 7,14 & 1 \\
\hline Nova Avanhandava & 0,00 & 0 \\
\hline Mogi-Guaçu & 7,14 & 1 \\
\hline Limoeiro & 50,00 & 7 \\
\hline Três Irmãos & 42,86 & 6 \\
\hline Ilha Solteira & 35,71 & 5 \\
\hline Jupiá & 50,00 & 7 \\
\hline Porto Primavera & 50,00 & 7 \\
\hline Média & 22,38 & 3,13 \\
\hline
\end{tabular}

A média do número de locos polimórficos por primer foi de 3,13 , e a da porcentagem de locos polimórficos, de 22,38. Os reservatórios de Chavantes, Jurumirim, Promissão e Nova Avanhandava foram excluídos das médias calculadas, por não apresentarem nenhum loco polimórfico, pois suas populações eram constituídas no máximo, por dois indivíduos. Já as populações LIM, JUP e PPR foram as mais variáveis, com $50 \%$ de locos polimórficos, ficando, desse modo, acima da média das demais populações.

Na Tabela 2 constam as distâncias genéticas calculadas com base no coeficiente de
Nei (1972). As análises dos dados revelaram que a maior parte dos acessos das populações estudadas apresentou grande semelhança.

Como era de se esperar, não houve grandes diferenças genéticas entre as plantas coletadas nos reservatórios localizados na mesma bacia hidrográfica em seqüência a jusante do rio Tietê,como é o caso de BAB, BAR, IBI, PRO, NAV e TRI, visto que a principal via de reprodução de alface-d'água é vegetativa.

O fato de a origem da alface-d'água não ter sido determinada definitivamente - sendo atribuída à América do Sul ou África - faz com que esta espécie possa ter sido introduzida e dispersada a partir de poucos materiais genéticos. Isso poderia justificar a similaridade genética revelada entre reservatórios de diferentes bacias, como é o caso de Barra Bonita e Salto Grande $(0,0093)$ e Limoeiro e Três Irmãos $(0,0178)$, distantes geograficamente. Outra questão que deve ser levada em conta é o fato de a porcentagem máxima de consistência dos nós do dendrograma ser de 9,09\%, indicando que o agrupamento dessas populações pode ter sido meramente ao acaso.

Observa-se, na Figura 2, o dendrograma de distância genética, no qual se verifica que 14 dos reservatórios estudados agruparam-se com indice de distância genética de no máximo 0,23 .

No entanto, a população de Jupiá revelou-se muito variada e elevou o índice de distância genética a 0,45. Em relação a Limoeiro, Jupiá apresentou a maior distância entre as 
Tabela 2 - Distância genética construída com base no coeficiente de Nei (1972), a partir de marcadores RAPD obtidos para as 15 populações de Pistia stratiotes

\begin{tabular}{|c|c|c|c|c|c|c|c|c|c|c|c|c|c|c|c|}
\hline. & BAB & BAR & IBI & CHA & SAG & JUR & PRO & JAG & NAV & MOG & LIM & TRI & ILS & JUP & PPR \\
\hline BAB & - & - & - & - & - & - & - & - & - & - & - & - & - & - & - \\
\hline BAR & 0,1377 & - & - & - & - & - & - & - & - & - & - & - & - & - & - \\
\hline IBI & 0,0447 & 0,1978 & - & - & - & - & - & - & - & - & - & - & - & - & - \\
\hline CHA & 0,0459 & 0,1973 & 0,0000 & - & - & - & - & - & - & - & - & - & - & - & - \\
\hline SAG & 0,0093 & 0,2087 & 0,0212 & 0,0209 & - & - & - & - & - & - & - & - & - & - & - \\
\hline JUR & 0,0459 & 0,1973 & 0,0000 & 0,0000 & 0,0209 & - & - & - & - & - & - & - & - & - & - \\
\hline PRO & 0,0459 & 0,1973 & 0,0000 & 0,0000 & 0,0209 & 0,0000 & - & - & - & - & - & - & - & - & - \\
\hline JAG & 0,1033 & 0,1121 & 0,0753 & 0,0749 & 0,1013 & 0,0749 & 0,0749 & - & - & - & - & - & - & - & - \\
\hline NAV & 0,0353 & 0,2603 & 0,0000 & 0,0000 & 0,0133 & 0,0000 & 0,0000 & 0,0966 & - & - & - & - & - & - & - \\
\hline MOG & 0,0444 & 0,1981 & 0,0000 & 0,0000 & 0,0213 & 0,0000 & 0,0000 & 0,0755 & 0,0000 & - & - & - & - & - & - \\
\hline LIM & 0,1000 & 0,2642 & 0,0836 & 0,0838 & 0,0782 & 0,0838 & 0,0838 & 0,1484 & 0,1096 & 0,0836 & - & - & - & - & - \\
\hline TRI & 0,1609 & 0,4011 & 0,1582 & 0,1569 & 0,1316 & 0,1569 & 0,1569 & 0,2576 & 0,1873 & 0,1587 & 0,0178 & - & - & - & - \\
\hline ILS & 0,0788 & 0,2297 & 0,0301 & 0,0310 & 0,0589 & 0,0310 & 0,0310 & 0,1158 & 0,0403 & 0,0298 & 0,0969 & 0,1462 & - & - & - \\
\hline JUP & 0,4340 & 0,5511 & 0,5316 & 0,5272 & 0,4347 & 0,5272 & 0,5272 & 0,4037 & 0,6444 & 0,5331 & 0,3171 & 0,2815 & 0,4323 & - & - \\
\hline PPR & 0,2644 & 0,4053 & 0,2448 & 0,2429 & 0,2455 & 0,2429 & 0,2429 & 0,2469 & 0,2907 & 0,2454 & 0,1384 & 0,1072 & 0,2217 & 0,1396 & - \\
\hline
\end{tabular}

BAB-Barra Bonita, BAR-Bariri, IBI-Ibitinga, CHA-Chavantes, SAG-Salto Grande, JUR-Jurumirim, PRO-Promissão, JAG-Jaguari, NAVNova Avanhandava, MOG-Mogi-Guaçu, LIM-Limoeiro, TRI-Três Irmãos, ILS-Ilha Solteira, JUP-Jupiá, PPR-Porto Primavera

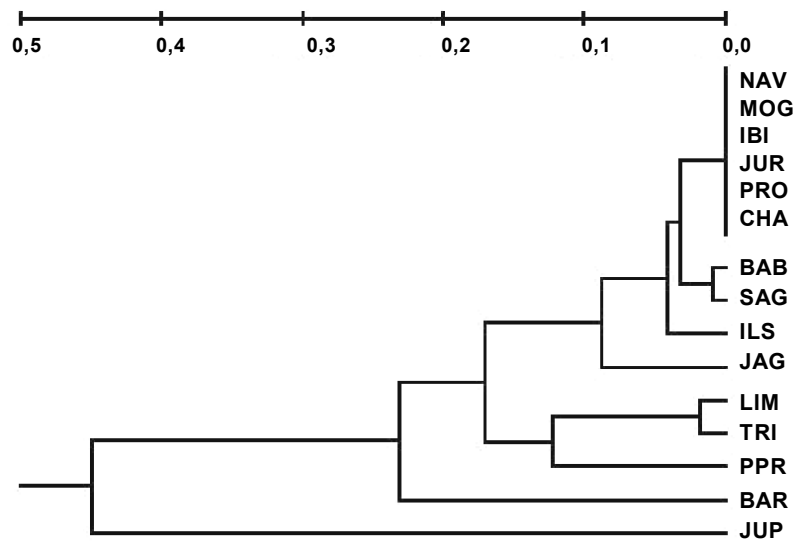

Figura 2 - Dendrograma de distância genética entre as populações de alface-d'água.

populações $(0,64)$, com $100 \%$ de consistência do resultado obtido. O reservatório de Jupiá deve apresentar fontes de contribuição de material vegetal mais complexas que os demais, por estar estrategicamente localizado de modo que seja um conversor de águas; essas contribuições podem ter sido excluídas aleatoriamente ao se realizar a amostragem das plantas. Em levantamento de flora, Cavenaghi et al. (2003) observaram que os reservatórios que apresentaram maiores níveis de infestação com plantas marginais e flutuantes foram Mogi-Guaçu, Barra Bonita, Ibitinga e Limoeiro, enquanto Promissão e Nova Avanhandava apresentaram maior infestação de plantas imersas. Esse comportamento da biomassa de plantas está diretamente ligado às características dos corpos hídricos ao longo dos rios, podendo causar alterações nas condições da água e, conseqüentemente, na flora aquática de Jupiá.

A reprodução sexuada em alface-d'água parece estar em processo de degeneração; no entanto, segundo Kissmann (1997), há uma eventual reprodução por sementes formadas em quantidades significativas quando existem polinizadores adequados. Cordo et al. (1981) sugerem que a alface-d'água pode ser nativa da América do Sul, devido à abundância de insetos regionais associados a essa planta. Em razão da grande variabilidade ocorrida em Jupiá, um estudo mais detalhado deve ser realizado, considerando suas particularidades para definir quais os fatores que mais influenciam o povoamento desse reservatório, pois se acredita que para algumas plantas aquáticas a ação antropocêntrica tenha contribuído como principal agente dispersor. 


\section{LITERATURA CITADA}

CARDOSO, L. R. et al. Variabilidade genética de acessos de aguapé coletados no estado de São Paulo. Planta Daninha, v. 20, p. 1-6, 2002.

CAVENAGHI, A. L. et al. Caracterização da qualidade de água e sedimento relacionados com a ocorrência de plantas aquáticas em cinco reservatórios da bacia do rio Tietê.

Planta Daninha, v. 21, p. 43-52, 2003. (Edição especial)

CORDO, H. A.; DELOACH, J. C.; FERRER, R. Biological studies on two weevils, Ochatina bruchi and Onychylis cretatus, collected from Pistia and other aquatic plants in Argentina. Ann. Entomol. Soc. Am., v. 74, p. 363-369, 1981.

KISSMANN, K.G. Pistia stratiotes L. In: Plantas infestantes e nocivas. 2.ed. São Paulo: BASF, 1997. p. $77-81$.

LODHI, M. A. et al. A simple and efficient method for DNA extraction from grapevine cultivars and Vitis sapequeis. Plant Mol. Biol. Rep., v. 12, p. 6-13, 1994.

MARTINS, D. et al. Caracterização genética de acessos de egéria (Egeria spp.) coletados no estado de São Paulo.

Planta Daninha, v. 21, p. 1-6, 2003.

MILLER, M. P. Tools for population genetics analyses (TFPGA) 1.3: A Windows program for the analysis of allozyme and molecular population genetic data, 1997. Disponível em: <http://herb.bio.nau.edul miller/tfpga.htm>. Acesso em: 16 out. 2004.
NEI, M. Genetic distance between populations. Am. Nat., v. 106 , p. 283-292, 1972.

RYAN, F. J. Identification of monoecious and dioecious Hydrilla with the RAPD assay. Davis: USDA. Aquatic Weed Control Investigations, 1993a. p. 60. (Annual Report)

RYAN, F. J. Identification of the monoecious biotype of Hydrilla in Tulare County, CA. Davis: USDA. Aquatic Weed Control Investigations, 1993b. p. 62. (Annual Report)

TANAKA, R. H. Prejuízos causados por plantas aquáticas. In: WORKSHOP SOBRE CONTROLE DE PLANTAS AQUÁTICAS, 1988, Brasília. Anais... Brasília. IBAMA, 1988. p. $36-38$.

WEISS, A. Survey of Egeria densa accessions for genetic similarity by Random Amplified Polymorphic DNA analysis (RAPDs). Davis: USDA. Aquatic Weed Control Investigations, 1997. p. 69-73. (Annual Report)

WILLIAMS, J. G. K.; KUBELIK, A. R. K.; LIVAK, J. L. DNA polymorphisms amplified by arbitrary "primer"s are useful as genetic markers. Nucleic Acids Res., v. 18, p. $6531-6535,1990$.

YEH, F. C. et al. Popgene, the user-friendly freeware for population genetics analysis. Molecular Biology and Biotechnology Centre, University of Alberta, Canada, 1997. (1 disquete). 